\title{
The Seasonal Distribution of Wild Camels (Camelus ferus) in Relation to Changes of the Environmental Conditions in Mongolia
}

\author{
Adiya Yadamsuren"1,2,3, Odonkhuu Daria ${ }^{3}$, Shaochuang Liu ${ }^{2}$ \\ ${ }^{1}$ Institute of Remote Sensing and Digital Earth, Chinese Academy of Sciences, Beijing, China \\ ${ }^{2}$ University of Chinese Academy of Sciences, Beijing, China \\ ${ }^{3}$ Wild Camel Protection Foundation Mongolia, Ulaanbaatar, Mongolia \\ Email: ya.adiya @gmail.com, a diya@wildcamels.mn, odonhuu.daria@gmail.com, liusc@irsa.ac.cn
}

How to cite this paper: Yadamsuren, A., Daria, O. and Liu, S.C. (2019) The Seasonal Distribution of Wild Camels (Camelus ferus) in Relation to Changes of the Environmental Conditions in Mongolia. Open Journal of Ecology, 9, 293-314.

https://doi.org/10.4236/oje.2019.98021

Received: April 1, 2019

Accepted: August 26, 2019

Published: August 29, 2019

Copyright $\odot 2019$ by author(s) and Scientific Research Publishing Inc. This work is licensed under the Creative Commons Attribution International License (CC BY 4.0).

http://creativecommons.org/licenses/by/4.0/

\begin{abstract}
The wild camel (Camelus ferus) is a critically endangered large ungulate, surviving in just three distinct populations located in the Taklamakan Desert, China; deserts near Lop Nuur, China; and in China and Mongolia within and adjacent to Mongolia's Great Gobi Strictly Protected Area (GGSPA). The population surviving in Mongolia remains poorly researched, but as few as 500 individuals may survive, although its distribution has remained relatively constant over the past 30 - 50 years. This study aimed at identifying potentially important environmental factors that influence the distribution of wild camels in Mongolia and predicting seasonal movement. We predicted distribution by season using presence only data and selected environmental predictors, including land surface temperature, normalized difference vegetation indices (NDVI), water sources, vegetation and soil. Model predictions revealed that land surface temperature in summer correlated significantly with wild camel distribution, with camels occurring in cooler areas. Abundance of biomass did not significantly correlate with camel distribution. Camels occurred in areas with intermediate levels of NDVI in most seasons, implying that they may base foraging decisions on forage quantity, not quality. Positive correlations of camel distribution with higher NDVI in summer $(P=0.03)$ suggests that they may prefer herbaceous species that appear after rainfall. Models indicate distance to water sources may be critical for camel distribution in all seasons. Camel occurrence correlated with areas containing shallow mountain soils in summer. Camels displayed no significant habitat correlations in other seasons, yet ranges differed among all seasons. Camels used a common region in spring, summer and autumn that we believe represents the core of the species' annual range. Wild camel distribution during winter var-
\end{abstract}


ied significantly from other seasons. Our modelling led to a predicted distribution range that was consistent with ranges described by previous research, indicating consistency between survey data and satellite tracking data.

\section{Keywords}

Seasonal Distribution, Environmental Variables, Gobi-Desert, Camelus ferus, Mongolia

\section{Introduction}

The world's deserts comprise about $17 \%$ of the earth's landmass and are home to surprising diversity of megafauna [1]. However, much of this diversity is under threat. Extinction rates are high and conservation efforts and finance have been limited compared to other biomes [2]. For example, of 14 large vertebrates that have historically occurred in the Sahara desert, four are now extinct in the wild, and the majority of others have disappeared from more than $90 \%$ of their historic range [2]. The Great Gobi was included in the UNESCO Biosphere Reserve system in 1991. In addition to Wild camels, GGSPA provides protection to several other species of large mammals listed in the Mongolian Red Book [3] including snow leopard (Uncia uncia), Khulan (Equus hemionus), Goitered Gazelle (Gazella subgutturosa), Argali (Ovis ammon), Ibex (Capra sibirica) and the endemic Gobi brown bear (Ursus arctos).

The extremes of environment that typify deserts has resulted in unique adaptations by desert species but has also made them especially sensitive to disturbance. Climate change, human encroachment for resource extraction (hunting and mining) and infrastructure (roading, fencing and railway) may be pushing many species toward extinction.

The conservation of desert megafauna is made challenging given their uncertain distributions and increasingly small population sizes within large desert areas. Surveying is difficult given the harsh environmental conditions. Therefore, the knowledge of population trends, identifying threats and proposing management solutions is frequently based on limited information. Improving our knowledge of how species use desert habitats can be used to validate population estimates, identify aspects of the landscape favoured or avoided and help generate hypotheses about threats. This has led to calls for more research focussed on desert species [2].

One example of a poorly understood yet charismatic desert species is the wild camel (Camelus ferus). It is a critically endangered ungulate that inhabits desert ecosystems of Central Asia. The wild camel was first documented by Przewalsky (1879) in the Lop Nur region of China in the late 1870s. Three remnant populations of wild camels remain in the Taklimakan Desert of China, the desert around Lop Nur in China, and in and around the Great Gobi Strictly Protected Area (GGSPA) of Mongolia (See Figure 1), [4]. There are numerous proposed 


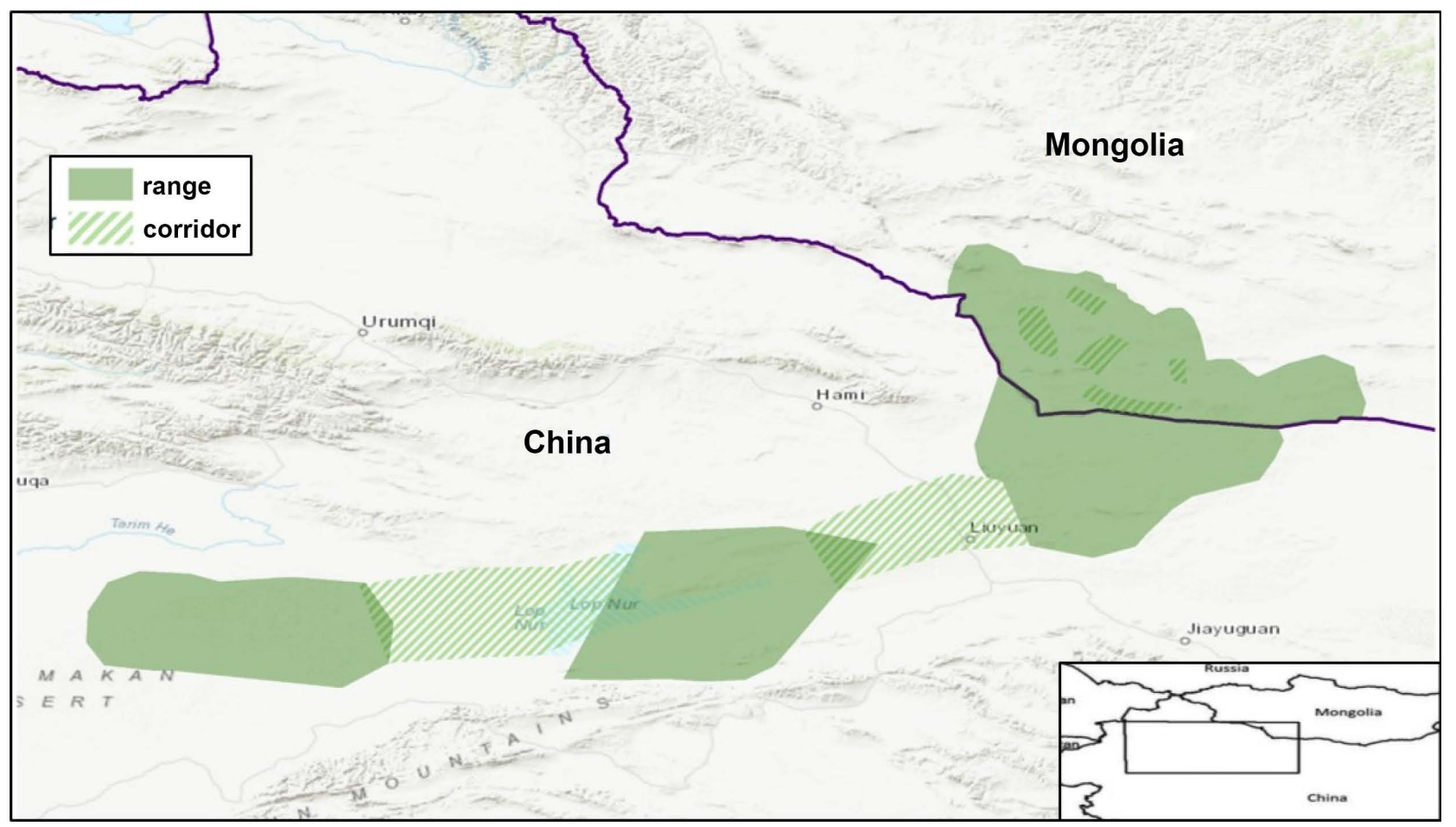

Figure 1. Wild Bactrian camel range in Mongolia and China, described by Adiya (2016).

threats to wild camel including its small population size, caused by suspected poaching in China and Mongolia, loss of habitat to mining efforts, and intentional and unintentional interbreeding with domestic Bactrian camels (Camelus bactrianus) [5].

The population of wild camels in Mongolia falls almost completely within the $45,000 \mathrm{~km}^{2}$ "A" section of GGSPA. The population of wild camels in Mongolia remains poorly studied, with highly variable estimates based on non-rigorous surveys [6]. Estimates ranged from 400 to 900 in the 1970s [5], $480-800$ in the 1980s, [4], $300-500$ in early the 1990s [7], and $1985 \pm 802$ SE in an aerial survey in 1997 [8]. Interpreting these estimates is difficult given the lack of rigorous sampling designs including a frequent bias toward searching mostly in areas where camels were thought to occur and extrapolating from this. Studying where camel are distributed within the GGSPAA and what landscape features are associated with this distribution can therefore better inform survey design and interpretation. Researchers have repeatedly observed wild camel concentrations during different times of the year and suggested different hotspots during calving (spring), rutting (winter) and as a reaction to seasonality in climate and vegetation [4] [9] [10]. In the most detailed recent study, Kaczensky et al. (2014) tracked seven collared individuals showing they used a total range of $28,410 \mathrm{~km}^{2}$ with a preference for intermediate areas of productivity and a proximity to water and an avoidance of steep slopes. This study aimed at identifying potentially important environmental factors that influence the distribution of wild camels in Mongolia and predicting seasonal movement. 
This study were to use tracking data from the above mentioned seven collared wild camel [11] and also four collared captive wild camels after release them in to the Gobi A from Breeding centre with additional habitat predictor variables to provide a more detailed analysis of predictors of camel presence. In addition to repeating tests for associations to landscape productivity (based on NDVI values), proximity to water and slope we also tested an association between camel presence and land surface temperature, water flow accumulation, soil type and an alternative characterization of vegetation type. Camels are uniquely adapted to sustain elevated body temperatures (ranging from $34^{\circ} \mathrm{C}$ at night to as high as $41^{\circ} \mathrm{C}$ during the day), and only above this threshold do camels begin to sweat and thus risk water loss [12]. We predicted camel presence would be defined within their thermal constraints and in interaction with vegetation and hydrology.

\section{Materials and Methods}

\subsection{Study Area}

The study area covers the Great Gobi A Strictly Protected Area (GGSPAA) in the Gobi Desert of Mongolia, situated between $95^{\circ} 15^{\prime}-99^{\circ} 40^{\prime} \mathrm{E}$ and $42^{\circ} 31^{\prime}$ $44^{\circ} 41^{\prime} \mathrm{N}$. The GGSPAA was established in 1976 by the Government of Mongolia and was designated as a World Biosphere Reserve in 1991 by the United Nations (See Figure 2). The Gobi Desert includes true desert and semi-arid desert habitats. Climate is harsh, with the temperatures ranging from $\left(-35^{\circ} \mathrm{C}\right)$ in winter to $\left(+40^{\circ} \mathrm{C}\right)$ in summer. Monthly precipitation averages under $50 \mathrm{~mm}$ in summer and below $10 \mathrm{~mm}$ in winter. With the average altitude of $1300 \mathrm{~m}$, the region consists of highlands with rocky outcrops and rolling hills broken by mountain massif and dry stream beds [10]. The main vegetation comprises of desert shrubs, such as saxaul (Haloxylon ammodendron), anabasis (Anabasis brevifolia), ephedra (Ephedra przewalskii), salsola (Salsola arbuscula), and reaumaria (Reaumuria songarica) [13]. In areas that receive sufficient rainfall, annuals and perennials become dominant in late summer and autumn. Open water is restricted to about 40 springs (not all of which are permanent), primarily located in or near mountain ranges. Lush oasis vegetation surrounds several springs and consists of reed beds (Phragmites australis), poplar trees (Populus euphratica), and tamarisk (Tamarix ramosissima) stands [14]. Pasture productivity is primarily precipitation driven and subject to high intra- and interannual fluctuations [14].

We used wild camel presence locations from 7 collared individuals between Oct 2002-March 2004 and May 2007-Sep 2008 (See Table 1) as previously reported in Kaczensky et al. (2014). In brief, camels were fitted with GPS-Argos satellite collars. Six collars had a location accuracy of \pm 150 meters and we obtained the remaining collar's locations using the Doppler shift method from the Argos satellite systems. The positional errors of the Doppler shift method fall into 3 categories: (1) $\pm 150 \mathrm{~m},(2) \pm 350 \mathrm{~m}$ and (3) $\pm 500 \mathrm{~m}$. We obtained 3356 


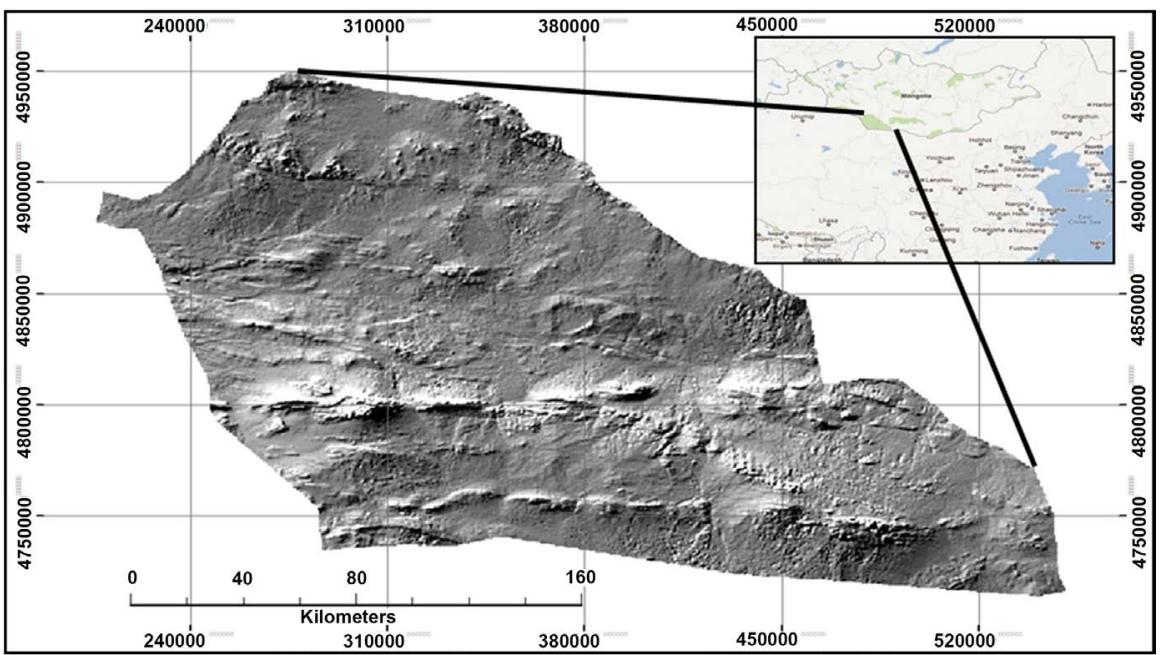

Figure 2. Study area: Great Gobi “A” Strictly Protected Area, Mongolia.

Table 1. Description of wild camels (Camelus ferus) tracked with telemetry units and accuracy of telemetry fixes.

\begin{tabular}{ccccc}
\hline Collar ID & Sex & Age & Precision of error $(\mathrm{m})$ & \# of points \\
\hline \multirow{2}{*}{1} & Female & Adult & $1: \pm 150$ & \\
& & & $2: \pm 350$ & 1103 \\
2 & Male & Bull & $3: \pm 1000$ & \\
25778 & Female & $11-12$ (Pregnant) & \pm 150 & 20 \\
25805 & Male & Young & \pm 150 & 687 \\
25915 & Female & Young & \pm 150 & 13 \\
70348 & Male & $9-10$ & \pm 150 & 194 \\
70350 & Male & Young & \pm 150 & 81 \\
& & Total & & 1258 \\
& & & & 3356 \\
\hline
\end{tabular}

wild camel locations during 35 months and data were pooled by month (See Table 2). Please see Kaczensky et al. (2014) for full details.

\subsection{Data Analysis}

We used presence-only data and the software MaxEnt [15] to model the distribution of wild camels and their interactions with environmental variables. We divided our sighting data into the four dominant seasons including spring (March, Apr and May), summer (June, July and Aug), autumn (Sept, Oct and Nov) and winter (Dec, Jan and Feb). We applied the higher accuracy AUC (higher predictive accuracy) in the MaxEnt algorithm which improved predictive accuracy substantially. MaxEnt produces two types of response of camel presence to environmental variables: 1) each variable's response curve averaged by other predictor variables and 2) each variable's response curve created using only the variable itself. Predictor variables included those previously reported by Kaczensky et al. (2014); that is NDVI, proximity to water and slope. We then 
Table 2. Distribution of wild camel (Camelus ferus) telemetry locations $(\mathrm{n}=3356)$ by month and year.

\begin{tabular}{ccccccccccccc}
\hline Year & Jan & Feb & Mar & Apr & May & Jun & Jul & Aug & Sep & Oct & Nov & Dec \\
\hline 2002 & - & - & - & - & - & - & - & - & & 7 & 101 & 109 \\
2003 & 108 & 94 & 103 & 95 & 109 & 105 & 74 & 68 & 70 & 64 & 2 & 4 \\
2004 & 5 & 1 & 4 & - & - & - & - & - & - & - & - & - \\
2007 & - & - & - & - & 51 & 181 & 179 & 173 & 173 & 165 & 161 & 181 \\
2008 & 200 & 190 & 203 & 147 & 149 & 27 & 28 & 12 & 13 & - & - & - \\
Total & 313 & 285 & 310 & 242 & 309 & 313 & 281 & 253 & 256 & 236 & 264 & 294 \\
\hline
\end{tabular}

included four additional parameters, land surface temperature (LST), flow accumulation, soil type and a modified vegetation type.

To investigate how wild camels responded to temperature, we extracted monthly mean LST layers from MODIS Aqua (1 km, Version 5) satellite imagery. We obtained the imagery from the "IRI/LDEO Climate Data (http://iridl.ldeo.columbia.edu) Library." We used 35 monthly mean LST images from 2002 (Oc-Dec), 2003 (Jan-Dec), 2004 (Jan-Mar), 2007 (May-Dec) and 2008 (Jan-Sep) in our analyses. We pooled LST data by year. We extracted separate sets of LST values to test the difference between observed LST at camel locations against the mean LST value calculated for a random location. To calculate the mean LST for the surrounding environment, we created a circle with a radius of $25 \mathrm{~km}$ around each camel location $(\mathrm{n}=3279)$ and calculated the mean LST for each circle. We chose a distance of $25 \mathrm{~km}$ based on a spatial autocorrelation test we conducted for LST at camel locations (See Figure 3). The resulting correlogram showed an approximate distance of $25 \mathrm{~km}$, at which the correlation coefficient between observed LST values approached zero. We used a paired two-sample $t$-test to test for significance between mean LST at camel locations and mean LST for the surrounding buffer area.

Flow accumulation was derived from locations of water points. 35 water bodies were recorded from surveys conducted in previous years to our study [16]. We extracted flow accumulation areas from each water point from digital elevation models (DEM) using the hydrology tool in the spatial analyst tool of ArcGIS (https://www.arcgis.com/home). We then created $500 \mathrm{~m} / 500 \mathrm{~m}$ buffer line for two sides from drainage lines. We recognised 20 different soil types distributed throughout the GGSPAA (See Table 3) and we sourced this data from the national soil map (1:1,000,000 scale) in the analysis). Finally, we include a subset of the 24 vegetation classes identified in the vegetation classification and subset from Mongolia's vegetation community map (1:1,000,000 scale) that are found within the GGSPAA (See Table 3). The area of each habitat was calculated and converted into a minimum mapping unit in ArcMap 10.2 (ESRI 2010).

We used wild camels GPS tracking data presence datasets in our modelling; therefore, we examined two modelling outputs. The first dataset consisted of mixed occurrence data that include camel sightings, fecal/foot track records, and 

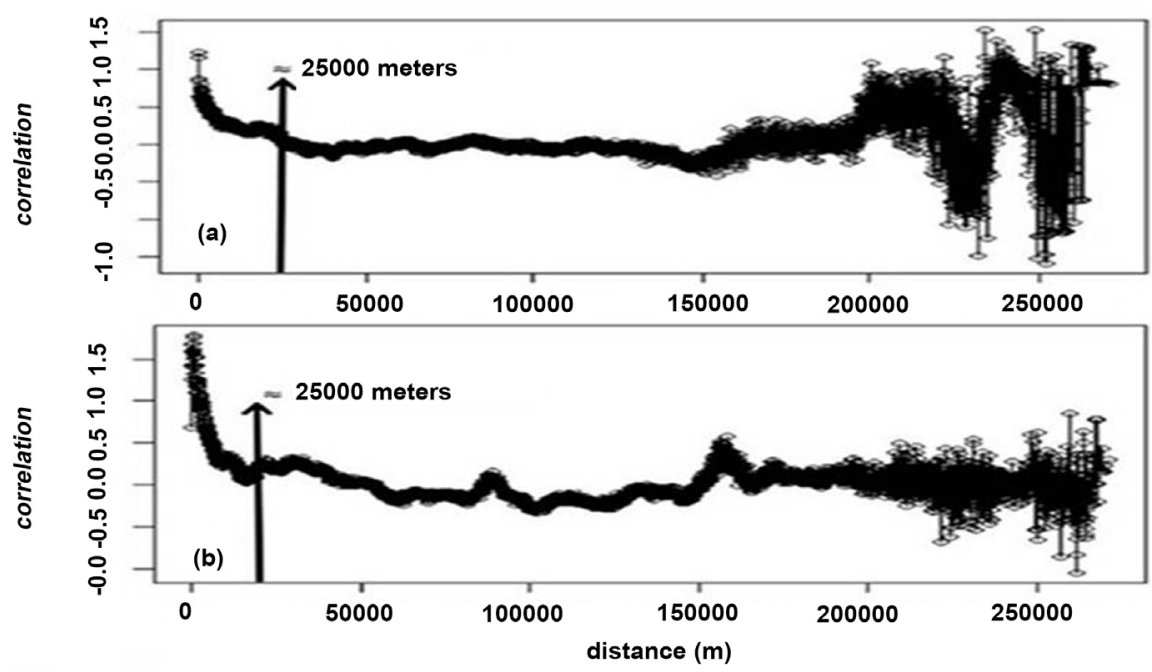

Figure 3. Correlogram showing the distance $(25 \mathrm{~km})$ at which the correlation coefficient (r) between the location of wild camels (Camelus ferus) and the surrounding buffer zones approach zero for land surface temperature values (upper) and normalized difference vegetation indexvalues (lower).

Table 3. Environmental variables used in wild camel (Camelus ferus) distribution modelling. $\mathrm{LST}=$ land surface temperature; NDVI = normalized difference vegetation index; $\mathrm{DEM}=$ digital elevation model.

\begin{tabular}{|c|c|c|c|c|}
\hline & Variables & Unit & Data type & Source \\
\hline 1 & $\begin{array}{l}\text { Land surface } \\
\text { temperature }\end{array}$ & $\begin{array}{l}\text { Celsius } \\
\text { degree }\end{array}$ & Continuous & MODIS/Aqua/1km/8Days/Version005 \\
\hline 2 & NDVI & $\begin{array}{c}\text { Scaled to } \\
(-1: 1)\end{array}$ & Continuous & SPOT-Vegetation 10-day composite \\
\hline 3 & $\begin{array}{l}\text { Distance to } \\
\text { water points }\end{array}$ & Meters & Continuous & Feature point layer from survey data \\
\hline 4 & $\begin{array}{l}\text { Distance to } \\
\text { drainage lines }\end{array}$ & Meters & Continuous & DEM 30 meters (Flow accumulation analysis) \\
\hline 5 & $\begin{array}{l}\text { Vegetation } \\
\text { classes }\end{array}$ & & Categorical & Mongolia's National Scale Classified Map $(1: 10,00,000)$ \\
\hline 6 & Soil types & & Categorical & Mongolia's National Scale Classified Map $(1: 1,000,000)$ \\
\hline
\end{tabular}

telemetry locations as described in the methodology section. The second dataset consisted solely of the telemetry locations of 7 collared wild camels; comprised of 3356 records. In this section, we refer to the first dataset as the "mixed" data model and second dataset as the "telemetry" data model.

\section{Results}

We found significantly lower mean LST was associated with camel presence during spring $(<0.001)$ and summer $(<0.001)$, and significantly higher LST during autumn as compared to the surrounding environment. No significant relationship between LST and camel presence was observed in winter (See Table 4). With respect to vegetation, we found significantly higher NDVI values were associated with camel locations in summer (0.064) and autumn (0.061) than in winter (0.050) and spring (0.046) (See Table 4). Compared with buffer zones, we 
Table 4. Comparison of mean land surface temperatures (LST in ${ }^{\circ} \mathrm{C}$ ) and mean normalized difference vegetation indices (NDVI) at wild camel (Camelus ferus) locations and within surrounding $25 \mathrm{~km}$ buffers. Comparison made using paired $t$-tests; $\mathrm{df}=$ degrees of freedom.

\begin{tabular}{|c|c|c|c|c|c|}
\hline Variable & & Spring & Summer & Autumn & Winter \\
\hline \multirow{5}{*}{$\operatorname{LST}\left({ }^{\circ} \mathrm{C}\right)$} & Camel locations & 25.49 & 43.17 & 21.48 & -21.10 \\
\hline & Buffer & 25.62 & 43.50 & 21.42 & -21.05 \\
\hline & $t$ & -3.2 & -5.77 & 1.81 & -1.14 \\
\hline & $\mathrm{df}$ & 860 & 846 & 755 & 814 \\
\hline & $P$ & $<0.001$ & $<0.001$ & 0.03 & 0.13 \\
\hline \multirow{5}{*}{ NDVI } & Camel locations & 0.046 & 0.064 & 0.061 & 0.050 \\
\hline & Buffer & 0.048 & 0.065 & 0.061 & 0.049 \\
\hline & $t$ & -4.47 & -1.8 & -0.21 & 4.37 \\
\hline & $\mathrm{df}$ & 860 & 846 & 755 & 891 \\
\hline & $P$ & $<0.001$ & 0.03 & 0.41 & $<0.001$ \\
\hline
\end{tabular}

found significantly higher NDVI values were associated with camel locations in winter, but significantly lower values in summer and spring (See Table 4).

Mixed data model. Jackknife tests of the mixed model found that distance to water points constituted the most important variable for all seasons except autumn (See Figure 4 and Table 5). In autumn, the categorical variables soil and vegetation exerted greater influence on the models than did distance to water. In all other seasons, soil and vegetation types represented the second and third most important variables. Alternatively, distance to drainages contributed the least to the mixed model in all seasons. LST contributed more to the model in winter than it did in other seasons. In all cases, NDVI contributed little to the models.

We compared response curves for LSTs each season (See Figure 5 and Table 5). Summer LST at camel locations ranged from $30^{\circ} \mathrm{C}$ to $50^{\circ} \mathrm{C}$, with a mean LST of $43.1^{\circ} \mathrm{C}$. Our model showed a high probability $(P=0.8)$ of camels associating with low LST during summer, with that probability decreasing as LST increases. Response curves for NDVI showed positive relationships (See Figure 6). For example, in summer, as NDVI increased from 0.04 to 0.14 , the probability of camel presence increased from 0.0 to 0.8 . However, although predicted NDVI peaked at $0.14(P=0.65)$, we observed more camels when NDVI was $0.1-0.12$. In addition, we found a negative relationship between NDVI and probability of camel presence in autumn and winter. Mean NDVI in the study area reached a maximum of 0.14 in summer and minimum of 0.04 in winter (See Figure 6). Overall, wild camel locations correlated most strongly with intermediate ranges of NDVI (0.06 - 0.08).

The mixed model predicted the highest probability $(P>0.60)$ of camel occurrence at a distance $10 \mathrm{~km}$ from a water point for all seasons (See Figure 7). In 


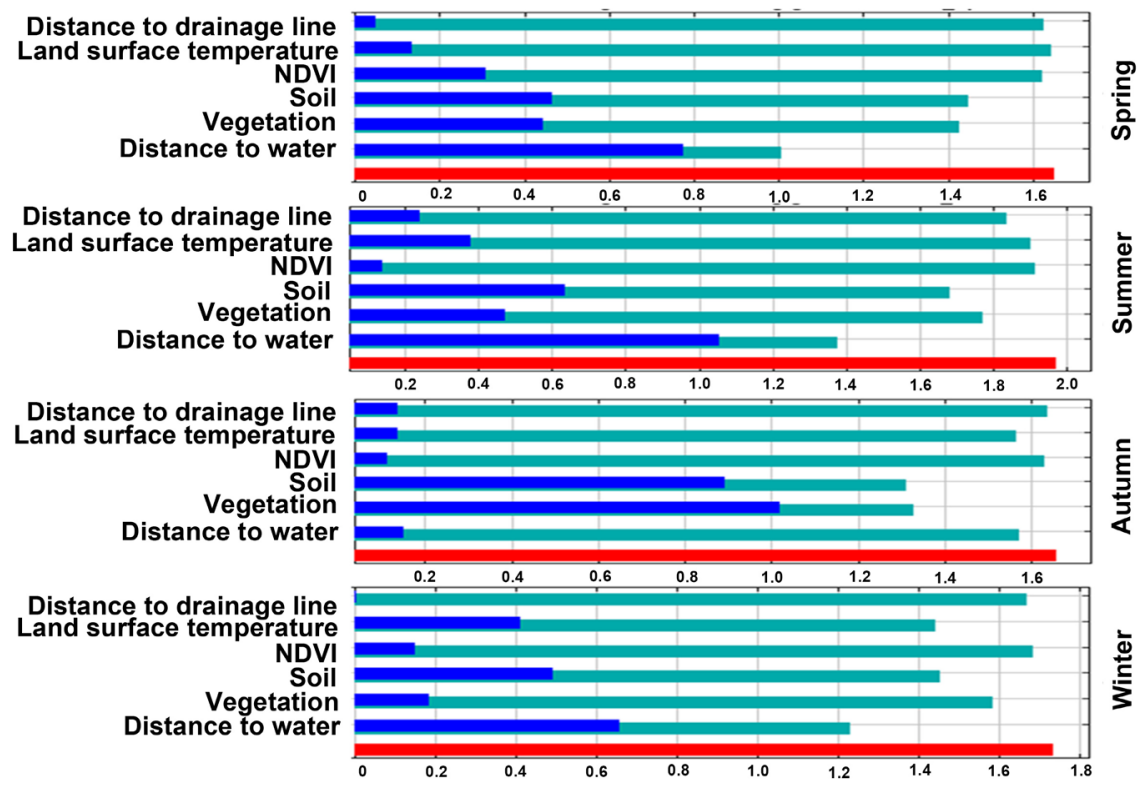

Figure 4. Results of jackknife tests examining the importance of environmental variables to a mixed model of wild camel (Camelus ferus) locations. The mixed model uses wild camel locations from telemetry, direct observations, and tracks.
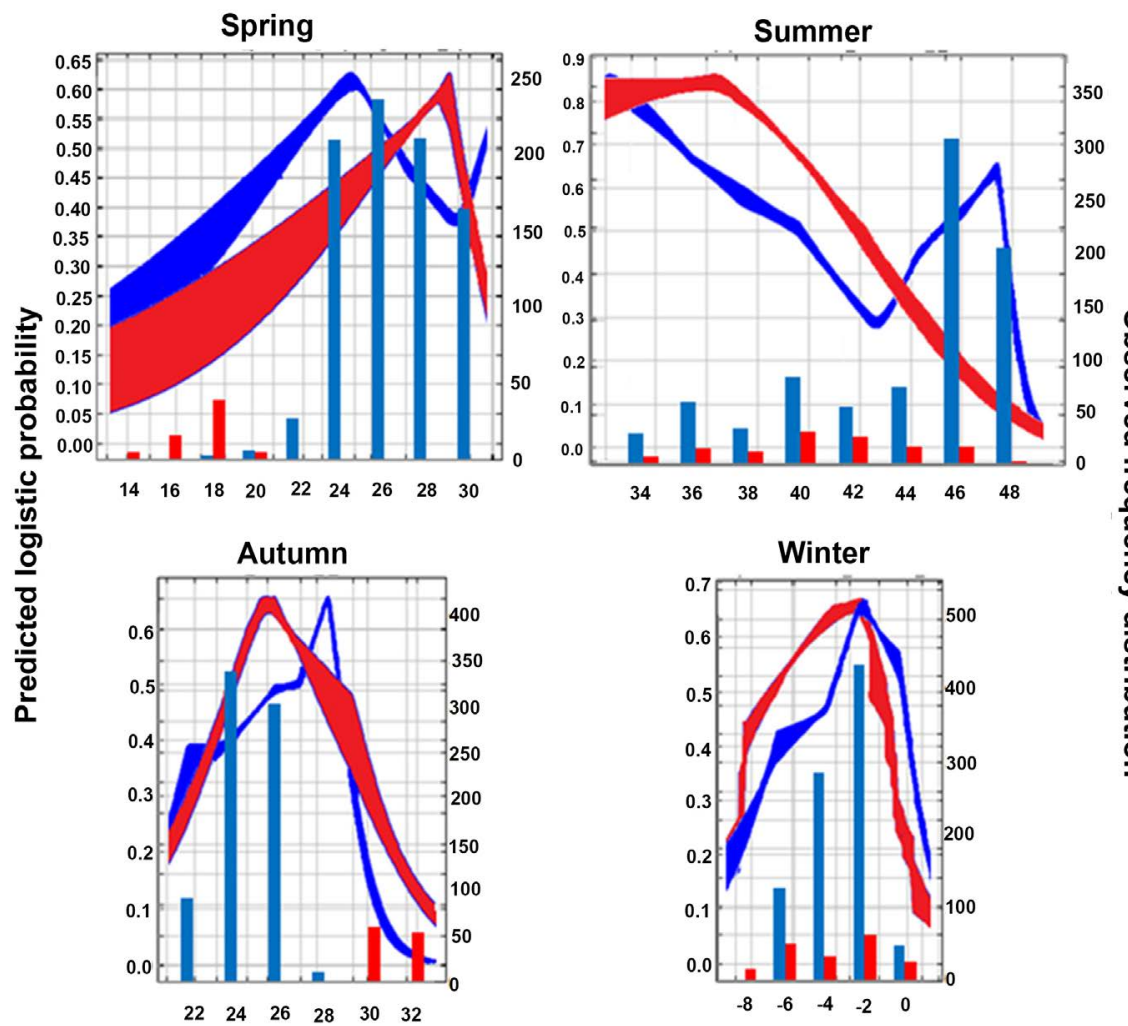

Figure 5. Response curves of land surface temperatures $\left({ }^{\circ} \mathrm{C}\right.$, $\mathrm{x}$ axis $)$ predicted from modelling wild camel (Camelus ferus) locations. Histograms show the frequency distribution of camel locations observed at each temperature. Blue: Telemetry data model, Red: Mixed data model. The telemetry data model uses only wild camel locations obtained from telemetry, while the mixed data model also includes locations from direct observations and tracks. 

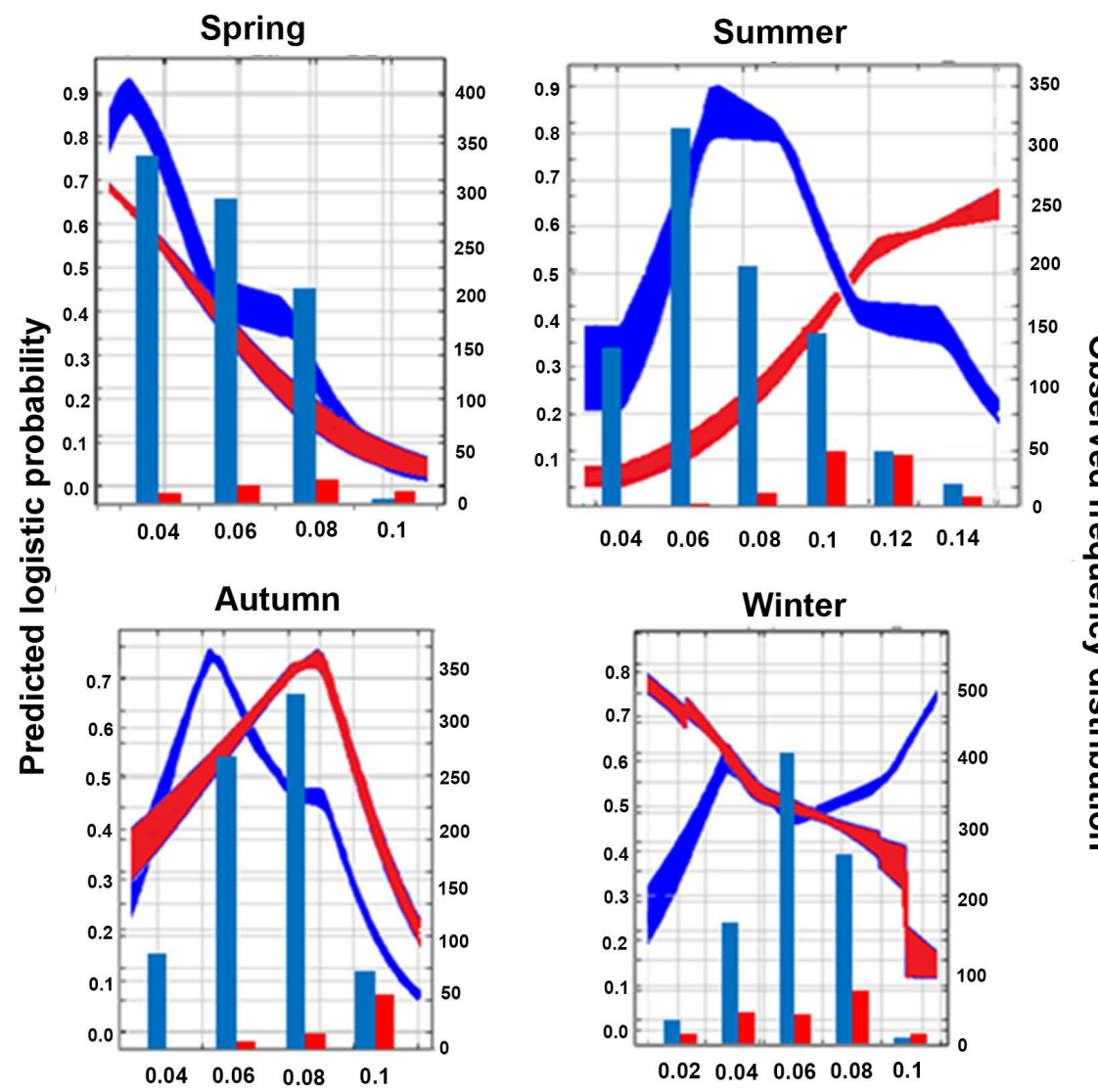

Figure 6. Response curves of normalized difference vegetation index (NDVI) values predicted from the modelling wild camel (Camelus ferus) locations. Histograms show the frequency distribution of camel locations observed at each NDVI value. Blue: Telemetry data model, Red: Mixed data model. The telemetry data model uses only wild camel locations obtained from telemetry, while the mixed data model also includes locations from direct observations and tracks.

Table 5. VIF values from multi-collinearity test shown in 4 seasons. NDVI = normalized difference vegetation index.

\begin{tabular}{ccccc}
\hline Variables & Spring & Summer & Autumn & Winter \\
\hline NDVI & 1.69 & 2.68 & 2.14 & 1.71 \\
Land surface temperature & 2.42 & 3.96 & 3.21 & 1.33 \\
Distance to water points & 1.67 & 1.99 & 1.86 & 1.50 \\
Distance to drainage lines & 1.51 & 1.45 & 1.50 & 1.22 \\
\hline
\end{tabular}

autumn, the model also predicted a relatively high probability of occurrence at $40 \mathrm{~km}$ from water points. Yet, overall, in all seasons the model demonstrated a rapidly decreasing probability of finding camels as the distance to water points increased. Similarly, for all seasons except summer, the model predicted a general trend of a lower probability of camel occurrence with increasing distance from drainages (See Figure 8). During summer, the model predicted just the opposite; a higher probability of occurrence with greater distances from drainages. 


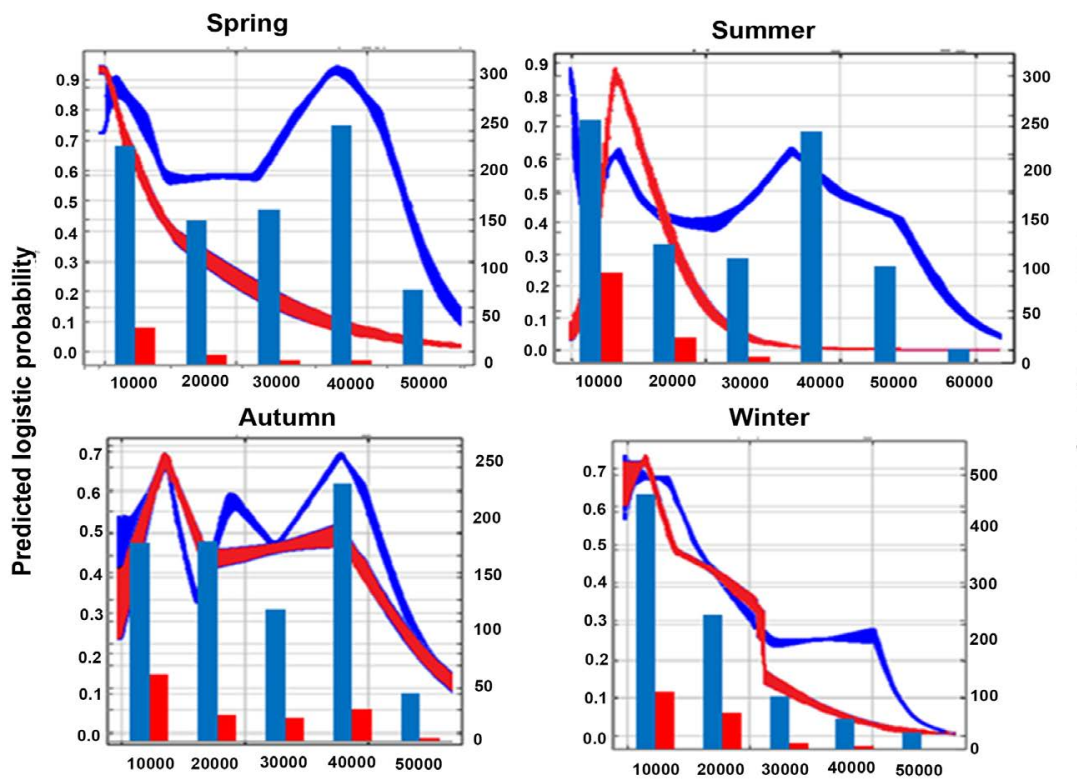

Figure 7. Response curves of distance to water points predicted from the modelling wild camel (Camelus ferus) locations. Histograms show the frequency distribution of camel locations observed at distance to a water point. Blue: Telemetry data model, Red: Mixed data model. The telemetry data model uses only wild camel locations obtained from telemetry, while the mixed data model also includes locations from direct observations and tracks.

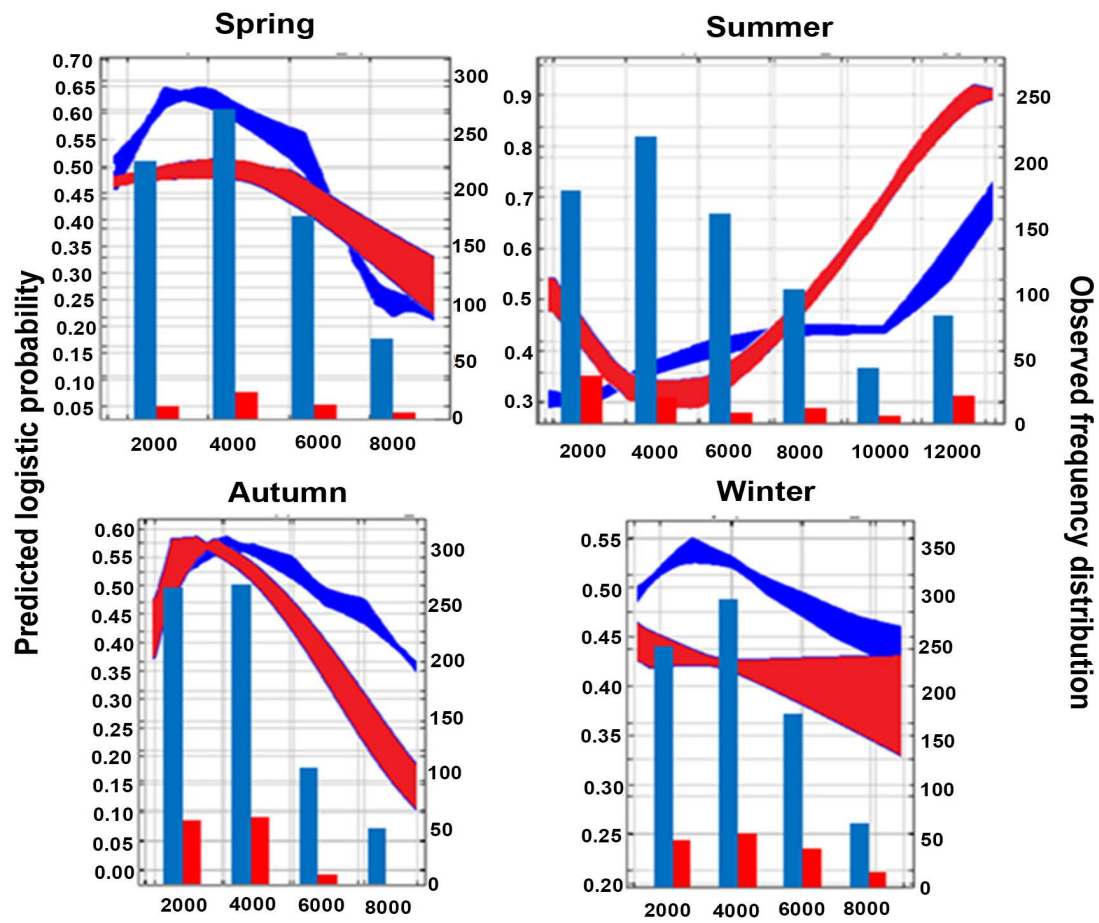

Figure 8. Response curves of distance to drainages predicted from the modelling wild camel (Camelus ferus) locations. Histograms show the frequency distribution of camel locations observed at each distance to a drainage. Blue: Telemetry data model, Red: Mixed data model. The telemetry data model uses only wild camel locations obtained from telemetry, while the mixed data model also includes locations from direct observations and tracks. 
Modelling predicted camel occurrence with specific types of the two categorical variables used; vegetation and soil types (Table 6). The model found the highest correlation between camel occurrence and shrub land communities in all seasons and strong correlations of occurrence with forbs were in summer. Camel occurrence correlated with shallow mountain brown soils in summer, but soils of steppe valleys and depressions (grey-brown extra arid soils) during the other seasons (See Figure 9).

Telemetry data model. Jacknife tests of the telemetry data model found that distance to water points constituted the most important variable only in winter, while vegetation was most important in spring and summer and soils most important in autumn (See Table 7). Overall, vegetation, soil type, NDVI, and distance to water sources represented the most important variables, while LST and especially distance to drainages exerted the weakest influence in the models. Compared to mixed data models, NDVI showed greater importance in telemetry data models.

As in the mixed data model, the telemetry model predicted a higher probability of camel occurrence in areas with low LST in summer. Both the mixed and telemetry models predicted the highest probability of camel occurrence at $30^{\circ} \mathrm{C}$ in summer, with the probability decreasing as LST became hotter. In general, during summer, the model predicted a decrease in probability of camel occurrence as LST increased from $32^{\circ} \mathrm{C}$ to $50^{\circ} \mathrm{C}$. However, the response curve rapidly increased from $44^{\circ} \mathrm{C}$ to $48^{\circ} \mathrm{C}$, the same range as that observed camel occurrence

Table 6. Positive correlations between wild camel (Camelus ferus) locations and vegetation and soil types predicted from mixed and telemetry data modelling. The telemetry data model uses only wild camel locations obtained from telemetry, while the mixed data model also includes locations from direct observations and tracks.

\begin{tabular}{|c|c|c|c|c|c|}
\hline Variable & Category & Spring & Summer & Autumn & Winter \\
\hline \multicolumn{6}{|c|}{ Mixed (observed) data model } \\
\hline \multirow{3}{*}{ Vegetation } & Perennial herbs with shrubs & & + & & \\
\hline & Annual forbs (Onion) with shrubs & & + & & \\
\hline & $\begin{array}{c}\text { Shrubs (Saxaul, Salsola, Ephedra, } \\
\text { Zygophyllum spp.) }\end{array}$ & + & + & + & + \\
\hline \multirow{3}{*}{ Soil } & Shallow mountain brown soil & & + & & \\
\hline & Soil of steppe valley and depression & & & & \\
\hline & (grey-brown extra arid soil) & + & & + & + \\
\hline \multicolumn{6}{|c|}{ Telemetry data model } \\
\hline \multirow{3}{*}{ Vegetation } & Perennial herbs with shrubs & & & + & \\
\hline & Annual forbs with shrubs & & + & & + \\
\hline & $\begin{array}{l}\text { Shrubs (Saxaul, Sympegma, Nitraria, } \\
\text { Anabasis, Zygophyllum spp.) }\end{array}$ & + & + & + & + \\
\hline \multirow{3}{*}{ Soil } & Shallow mountain brown soil & & + & & + \\
\hline & Soil of steppe valley and depression & & & & \\
\hline & (grey-brown extra arid soil) & + & & + & + \\
\hline
\end{tabular}


Table 7. Percentage of variable contributions to mixed data and telemetry data model outputs used to describe wild camel (Camelus ferus) habitat. Highlighted percentages indicate significant variables. NDVI = normalized difference vegetation index. The telemetry data model uses only wild camel locations obtained from telemetry, while the mixed data model also includes locations from direct observations and tracks.

\begin{tabular}{|c|c|c|c|c|c|}
\hline Model & Variables & Spring & Summer & Autumn & Winter \\
\hline \multirow{6}{*}{ Observed data } & Distance to drainage lines & $1.5 \%$ & $9.8 \%$ & $1.5 \%$ & $1.3 \%$ \\
\hline & Land surface temperature & $0.3 \%$ & $4.3 \%$ & $7.0 \%$ & $21.8 \%$ \\
\hline & NDVI & $3.5 \%$ & $1.7 \%$ & $0.7 \%$ & $2.0 \%$ \\
\hline & Soil types & $22.4 \%$ & $20.8 \%$ & $44.3 \%$ & $28.2 \%$ \\
\hline & Vegetation types & $27.1 \%$ & $14.8 \%$ & $38.4 \%$ & $9.1 \%$ \\
\hline & Distance to water points & $45.0 \%$ & $48.6 \%$ & $8.4 \%$ & $37.6 \%$ \\
\hline \multirow{6}{*}{ Telemetry data } & Distance to drainage lines & $1.2 \%$ & $5.0 \%$ & $1.6 \%$ & $2.2 \%$ \\
\hline & Land surface temperature & $6.9 \%$ & $14.0 \%$ & $7.5 \%$ & $9.3 \%$ \\
\hline & NDVI & $18.6 \%$ & $26.5 \%$ & $30.9 \%$ & $1.4 \%$ \\
\hline & Soil types & $17.4 \%$ & $16.7 \%$ & $31.6 \%$ & $16.4 \%$ \\
\hline & Vegetation types & $43.2 \%$ & $27.2 \%$ & $13.0 \%$ & $23.1 \%$ \\
\hline & Distance to water points & $12.7 \%$ & $10.5 \%$ & $15.4 \%$ & $47.6 \%$ \\
\hline
\end{tabular}

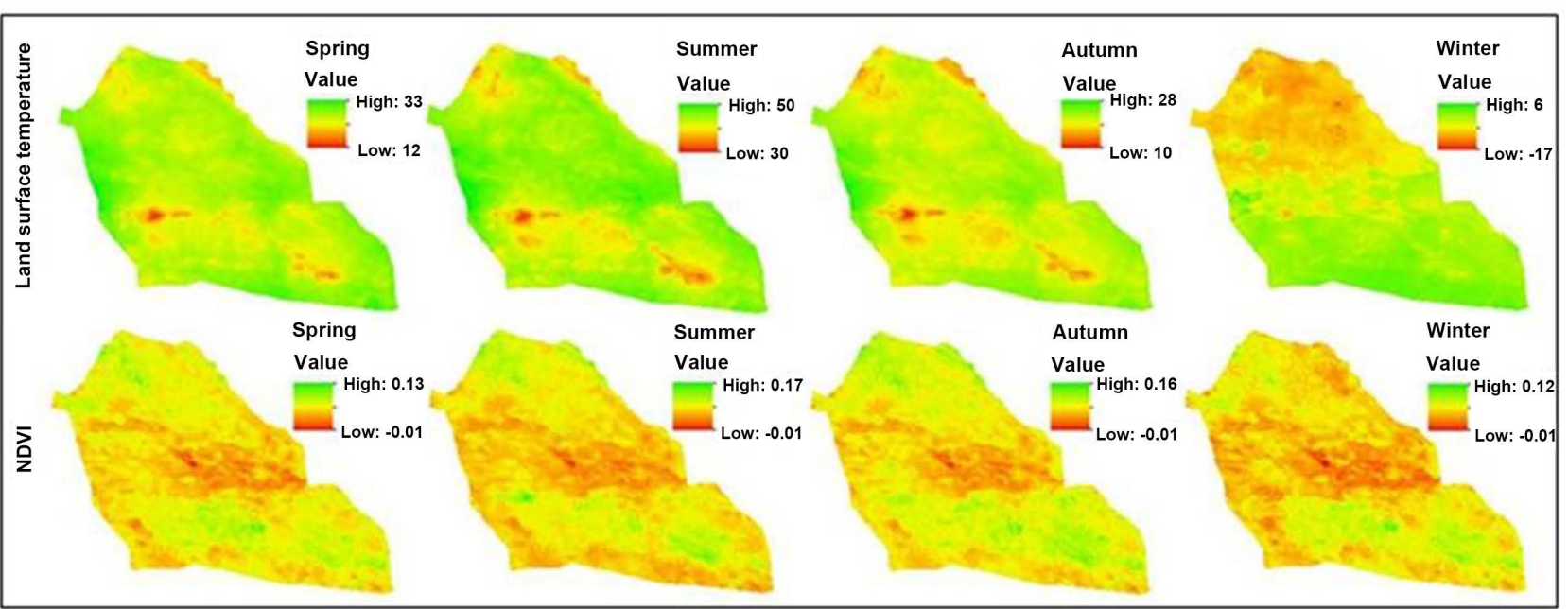

Figure 9. Seasonal land surface temperature $\left({ }^{\circ} \mathrm{C}\right)$ and normalized difference vegetation index (NDVI) maps used in modelling wild camel (Camelus ferus) locations.

reached its highest levels. During the other 3 seasons, probability of occurrence peaked at an intermediate LSTs; $23^{\circ} \mathrm{C}$ to $29^{\circ} \mathrm{C}$ in spring, $23^{\circ} \mathrm{C}$ in autumn, and $-4^{\circ} \mathrm{C}$ in winter.

In spring, summer, and autumn, the telemetry model generated a NDVI left skewed response curve in which the predicted probability of camel occurrence peaked at lower NDVI values. In winter, the model predicted a general increase in predicted camel occurrence with rising NDVI. Wild camels occurred in areas with an intermediate range of NDVI (mean $=0.06)$, suggesting that wild camel 
occurrence did not correlate biomass quality (Figure 10). For distance to water, the model predicted the highest probability of occurrence at $40 \mathrm{~km}$ away in spring, summer and autumn. Alternatively, in winter the model predicted the highest probability of occurrence at a distance of $10 \mathrm{~km}$.

Distance to drainages contributed least to the telemetry models. Similar to the mixed data model, the telemetry model predicted negative relationships in all seasons except summer. Except for summer, the model predicted the highest probability of occurrence at a distance of 2 to $4 \mathrm{~km}$. In summer, probability of occurrence increased with distance from drainages, peaking at $12 \mathrm{~km}$. The importance of variables in the telemetry data and mixed data models were similar. The telemetry model generated similar results to the mixed model for the categorical variables soil and vegetation classes. Shrub land communities again correlated strongly with camel occurrence in all seasons and both models found a high correlation between camel occurrence and herbaceous vegetation in summer. Both models also found that camel occurrence correlated with soils of steppe valleys and depressions (a grey-brown, extra arid soil) in all seasons, except summer when shallow, mountain, brown soils correlated more strongly.

Predicted distribution maps. Distribution ranges differed in each season or each of the 2 data sets. However, we identified common distribution areas in

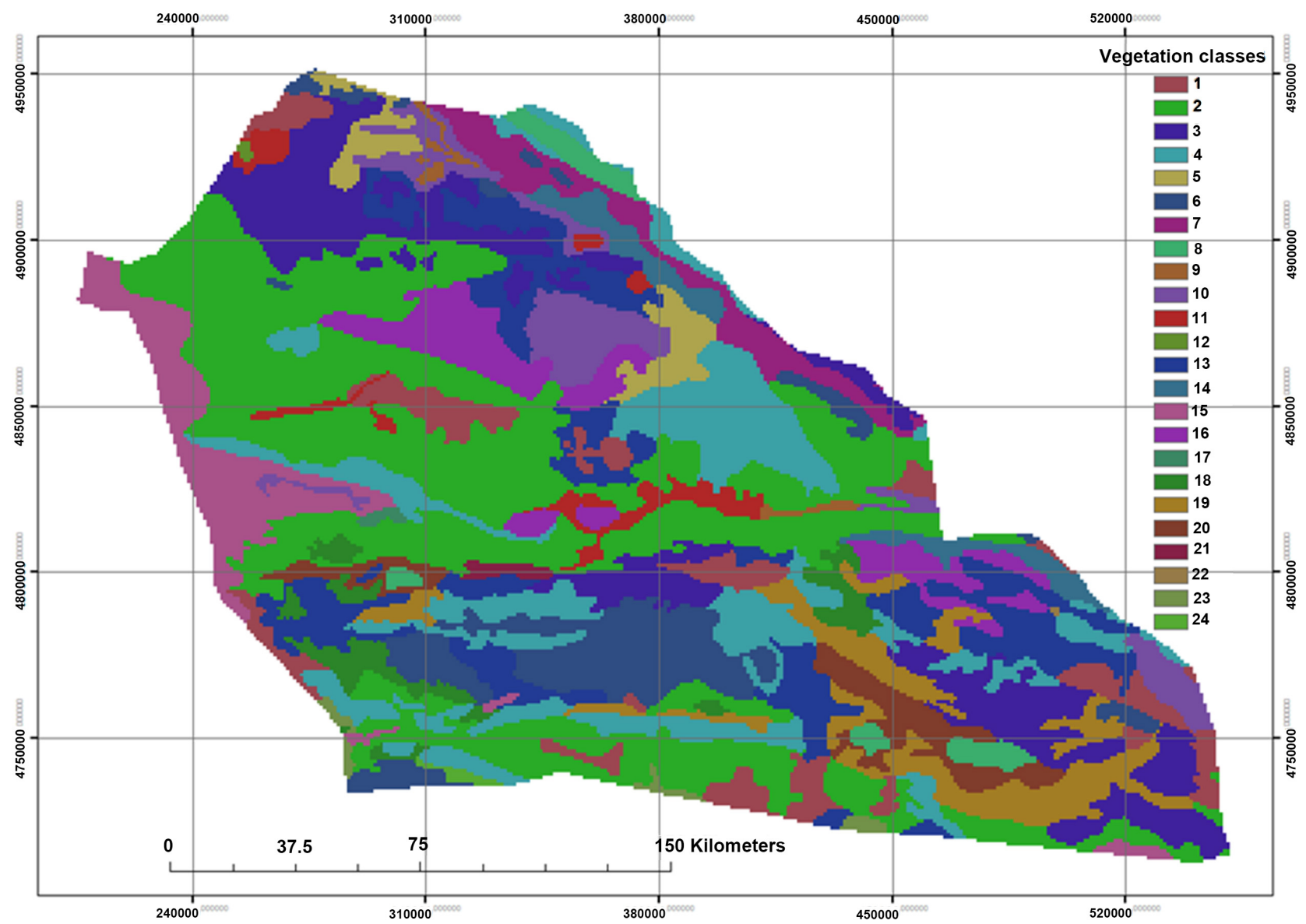

Figure 10. Vegetation map of the study area. 
summer, autumn and spring that we considered core areas within the species' annual range. These areas tend to fall in the centre and south-centre parts of GGSPA (See Figure 11).

\section{Discussion}

We investigated the relationship between wild camels and their environment in a part of the Mongolian Gobi on a seasonal basis using two sets of species presence data that differed in quality and quantity. We examined how environmental predictors changed through the seasons and how wild camel locations shifted in the face of these changing predictors. Extremely hot summers and cold winter characterize the study area. Our model confirmed our prediction that wild camels were more likely to occur in cooler areas during summer. Camels can raise their body temperature from $34^{\circ} \mathrm{C}$ to over $40^{\circ} \mathrm{C}$, helping these animals to avoid water loss through sweating [12]. Wild camels also avoid heat stress behaviourally, by grazing in the morning and evening and lying down during the day in summer [10].

GGSPA contains desert and semi-desert ecosystems that produce low biomass. Yet, our models did not find a strong correlation between higher NDVI

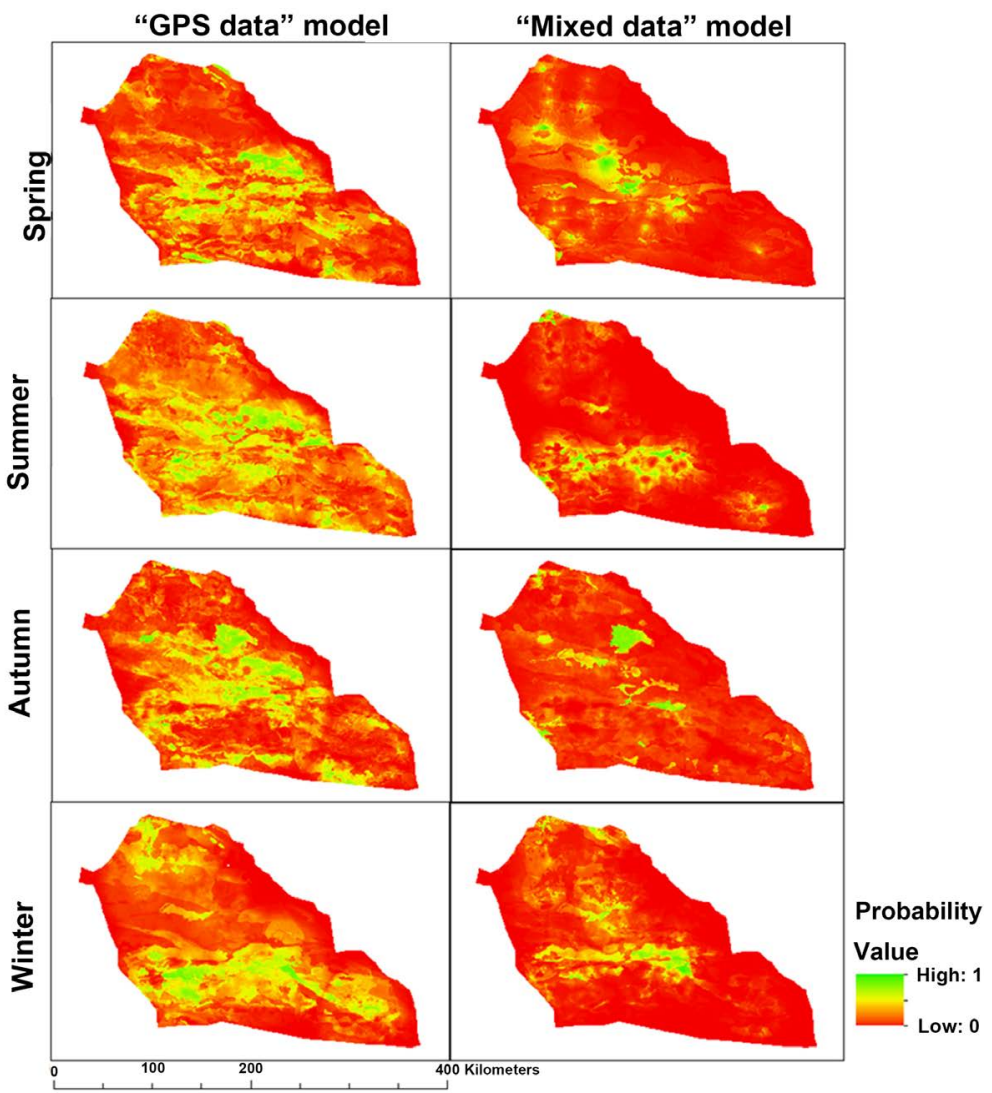

Figure 11. Predictive distribution maps of two models of wild camel (Camelus ferus) in each season. The telemetry data model uses only wild camel locations obtained from telemetry, while the mixed data model also includes locations from direct observations and tracks. 
(biomass) and wild camel occurrence. Instead, the models predicted greater wild camel occurrence in areas with intermediate levels of NDVI in most seasons, suggesting that camels focus on forage quantity, not quality. The exception was summer in which camel occurrence did correlate with higher NDVI, so camels occurred in areas with higher herbaceous vegetation that appears after rainfall. An analysis of wild camel stomach content consisted of shoots, twigs and stems of common shrubs of the Gobi desert, with herbaceous plants occurring in smaller quantities [5]. The relatively low levels of NDVI and scarce vegetation cover may lead this species to consume any available vegetation.

Shallow mountain soils correlated with wild camel's summer distribution. This typical chestnut soil is characterized as moderately deep and well drained, occurring on gently sloping hills where grasses and annual forbs temporarily appear in summer [13]. Thus, during summer, wild camel distribution correlated with the spatial co-existence of herbaceous plants, mountain soils and areas of lower temperature. The models did not predict soil preference in other seasons.

Wild camel distribution differed by season, but our models also predicted a common area of distribution in spring, summer and autumn that we consider the core range for the species in GGSPA. Predicted distribution from MaxEnt modelling largely matches the camel range described by other researchers [4] [9] suggesting consistency between survey and satellite tracking data.

The models predicted that that wild camel occurrence correlated with areas near water sources. Similarly, past surveys found abundant wild camel herds near water sources [11]. Oases occur in the upstream areas of dry river beds or the bottoms of valleys between ridges. Only at the oases do wild camels gather in large groups [10]. Likely because water represents a critical resource for wild camels that inhabit the extremely dry and hot landscape of GGSPA. By using drainages in mountain defiles wild camels can find shelter from cold winds in winters. In contrast, during summer camels shift their distribution away from drainages and to higher elevation areas with mountain soils and better herbaceous vegetation as discussed previously.

The mixed and telemetry data models generated different response curves. Data quantity and quality substantially affect model outputs and generally more data results in more accurate results. However, AUC tests found that the mixed model, which was based on fewer data, performed better $(\mathrm{AUC}=0.94)$ than the telemetry model, which was based on far more data $(\mathrm{AUC}=0.84)$ (See Figure 12).

McCarthy [9] and Tulgat \& Schaller [4] previously assessed seasonal distributions of wild camels that (See Figure 13 and Figure 14) closely matched the predicted ranges from our MaxEnt modelling. The telemetry data model used substantially more occurrence points $(\mathrm{n}=3356)$ than did the mixed data (only observations and tracks) model $(n=764)$, which may explain the differences we report between them affected our results. The distribution of the telemetry dataset 


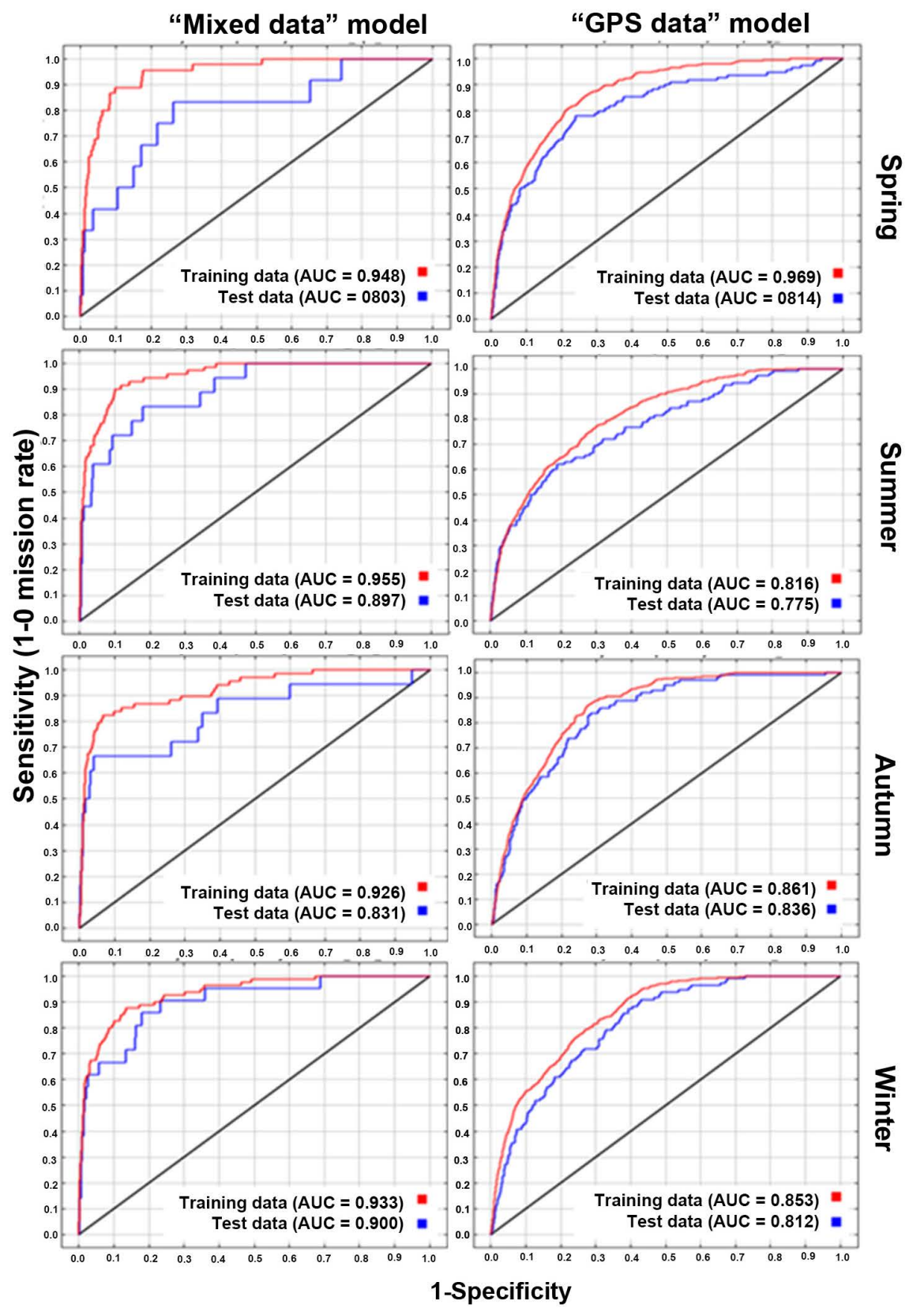

Figure 12. Area under receiver operating characteristics curves (AUC) of 8 different MaxEnt modelling evaluations to assess two models of wild camel (Camelus ferus) locations. The telemetry data model uses only wild camel locations obtained from telemetry, while the mixed data model also includes locations from direct observations and tracks.

provides a more realistic total range for wild camels than does the predicted distributions in our models. Exponential curves of environmental predictors from the incomplete data produced smoother curves than did the complete dataset. Fluctuations in the curve smoothness may have resulted from spatial autocorrelation of the full dataset of telemetry points.

Plant community variation on environmental gradients is associated with complex combinations of environmental factors and associated plant species 


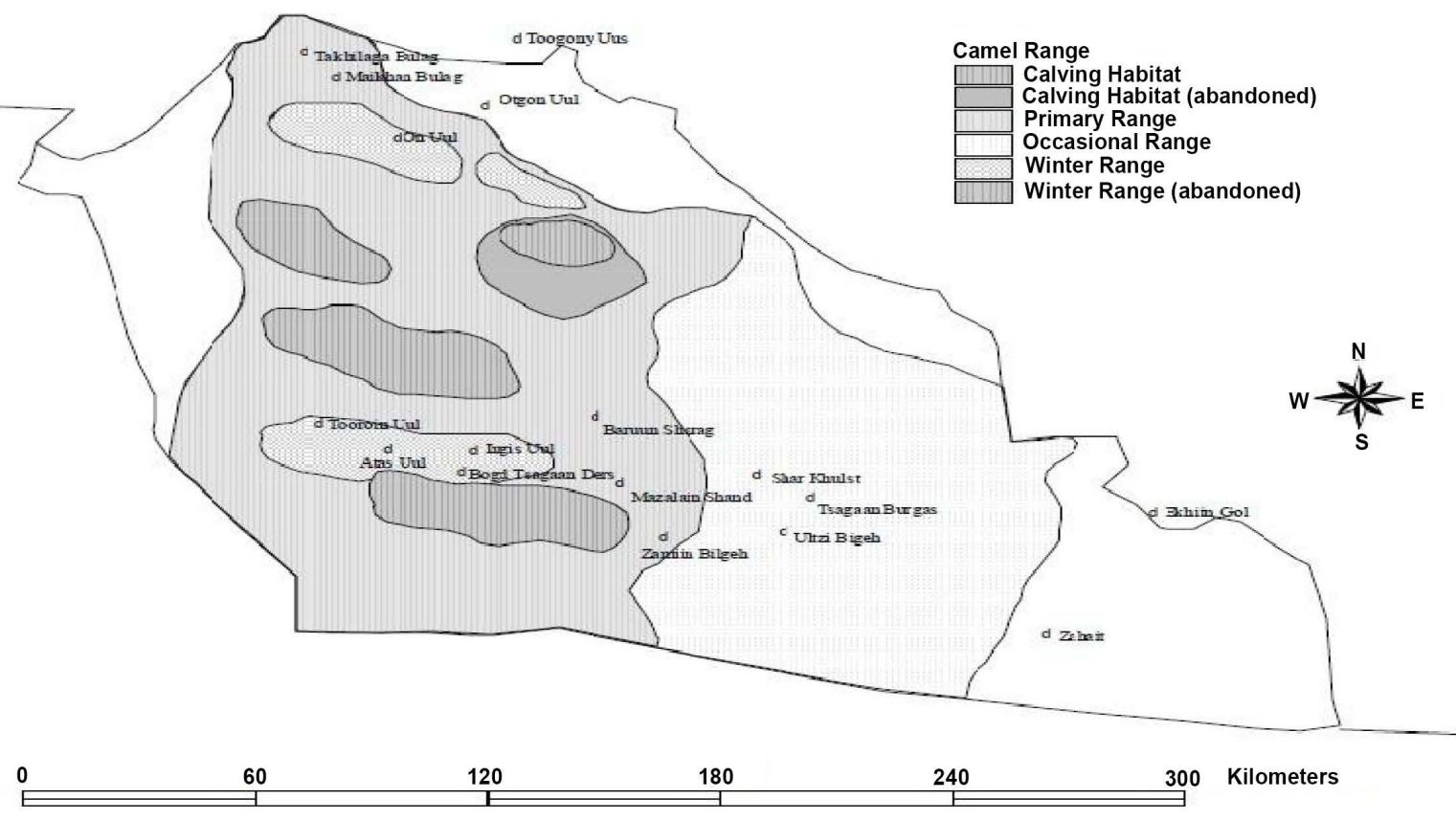

Figure 13. Wild Bactrian camel range described by McCarthy (2000).

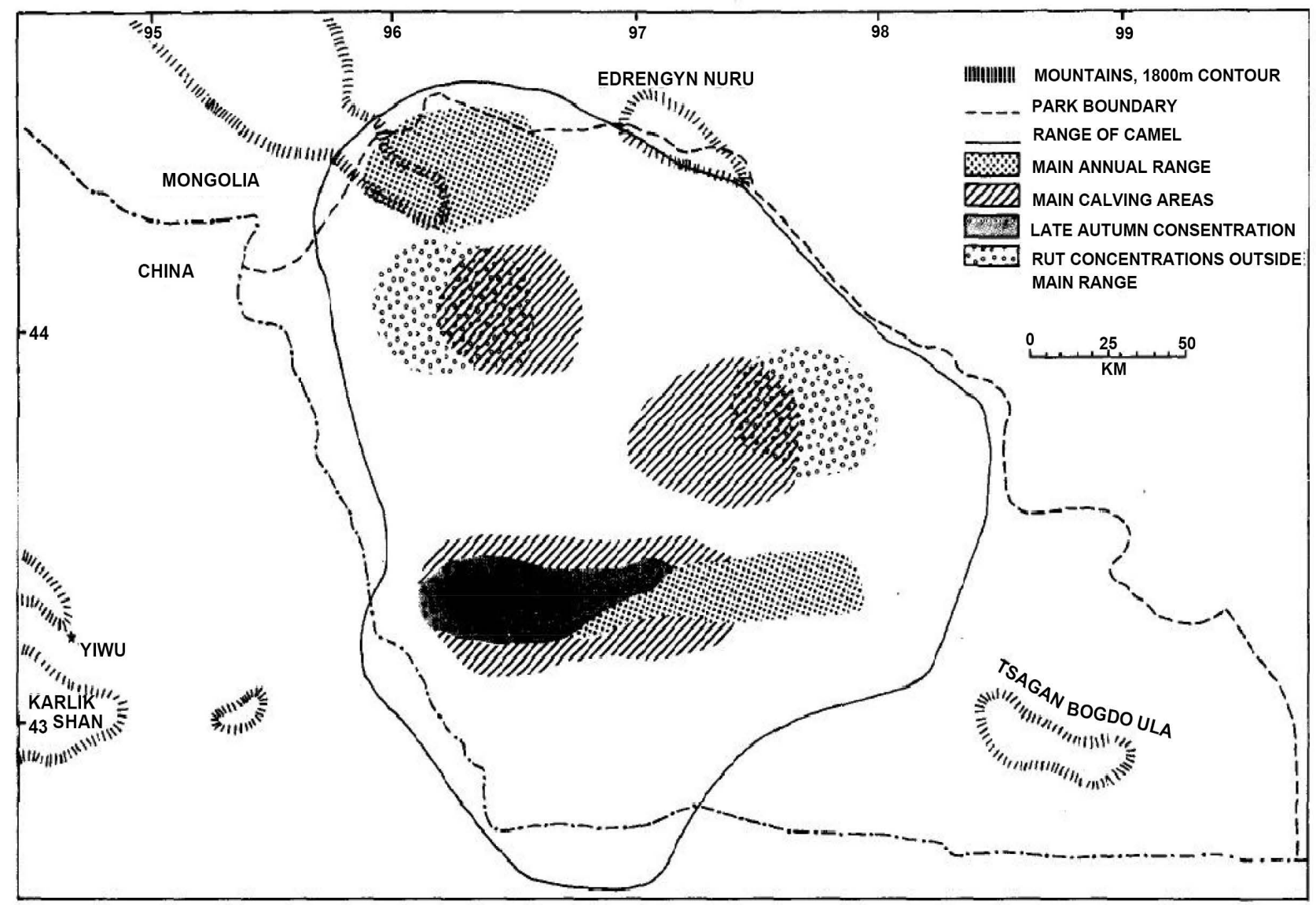

Figure 14. Wild Bactrian camel range described by Tulgat \& Schaller 1992). 
composition, richness and physiognomy, leading to distinct habitat attributes for animals such as seasonal resources, predation avoidance and shelter [17]. Environmental factors such as soil fertility, forage quality and water availability, which covary strongly with vegetation, may also influence human settlement, crop field and livestock distribution patterns. Development of detailed vegetation maps is, therefore, essential for 1) understanding the distribution of wild camel across a region, 2) research on wild camels 'home range and habitat use and 3) conservation planning.

Vegetation maps (See Figure 12) are especially useful for determining seasonal habitat use of collared and observed wild camels GPS locations may be obtained from a collared animal, which cannot easily be followed up on, especially in longest dried empty area is in northern Great Gobi A SPA. Currently, no detailed vegetation map exists for Great Gobi, with the best available product being the wild camel map of Great Gobi, which lacks the detail and accuracy needed for comprehensive wildlife habitat use studies and relation with seasonal distribution of wild camels.

Other important variables. The MaxEnt modelling approach uses species presence only records and, instead of the (pseudo) absence data used in other modelling algorithm such as GLM, GAM and BIOMOD, it uses background data randomly chosen from the study area [11]. Two main inputs for MaxEnt are species presence data and environmental data, such as temperature, rainfall, NDVI, soil types (see Figure 13) and elevation. The main objective of this approach is to calculate the probability distribution of maximum entropy (the most dispersed distribution, or closest to uniform) considering the set of constraints associated incomplete information of species distribution [15] [18]. MaxEnt modelling performed better than GARP, with higher AUC values [15]. We conducted MaxEnt modelling on a seasonal basis, with presence data divided into spring, summer, autumn and winter locations. We processed all environmental variables with a $1 \mathrm{~km}$ resolution using the WGS 84 datum with UTM Projection Zone 47N. We converted environmental layers into ASCII grid format to make them compatible with MaxEnt. As noted by Philips and Dudik (2008), applying the hinge feature tool in the MaxEnt algorithm improved model performance substantially. Therefore, we selected the hinge feature to get a realistic response curves from our modelling.

Explaining the response curves. MaxEnt produces 2 types of response curves: 1) each variable's response curve averaged by other predictor variables and 2) each variable's response curve created using only the variable itself. We used the second type of response curve to explain predicted probability by MaxEnt, because it is easy to interpret when strong correlations between variables exist. Alternatively, we overlapped the frequency distribution chart of predictor variables' values at camel presence points on the output response curves. Based on the ranges of values in the horizontal axis from the response curves, we binned the histogram charts of variable values at camel locations. Given an assumption that MaxEnt prediction is primarily based on the variable values at camel loca- 
tions, we can explain the behavior of response curves predicted by MaxEnt and interpret the relationship of variables against probability more easily.

Our preliminary multi-collinearity tests among continuous variables showed a high correlation between elevation land surface temperature. We therefore excluded elevation from additional analyses. As a results, we used 6 environmental variables in the modelling, of which 4 were continuous variables (Table 3). We tested the continuous variables for multi-collinearity and report the diagnostics values in Table 5. Since no VIF values exceeded 10, we used all variables in the modelling. We used two different presence datasets in our modelling; therefore, we examined two modelling outputs. The first dataset consisted of mixed occurrence data that include camel sightings, fecal/foot track records, and telemetry locations as described in the methodology section. The second dataset consisted solely of the telemetry locations of 7 collared wild camels; comprised of 3356 records. In this section, we refer to the first dataset as the "mixed" data model and second dataset as the "telemetry" data model. We produced 8 predictive camel distribution maps; one for each season using the mixed data model and the telemetry data model (See Figure 9).

Model evaluation. The most common evaluation approach for model performance is using receiver operating characteristic (ROC) curves and researchers have compared it using different algorithms [15] [18] [19] [20]. Area under ROC curve (AUC) is a threshold independent test formed by plotting sensitivity against "1-specificity". The proportion of observed presences correctly predicted describes sensitivity, whereas "1-specificity" is the proportion of observed absences correctly predicted [11].

Although, AUC test requires both presence and absence data, Philips et al (2006) has proven that MaxEnt modelling can produce AUC using randomly selected background data (pseudo-absence) in place of observed absence data.

\section{Acknowledgements}

We are particularly greateful to Great Gobi A SPA rangers and Wild Camel Protection Foundation Mongolian staff for logistics and hospitality. Funding was provided UNDP/GEF "Conservation of the Great Gobi Ecosystem and its Endangered Species" project, Institute of Biology of the Mongolian Academy of Sciences, Denver Zoological Foundation, Wild Camel Protection Foundation UK, Zoological Society of London's EDGE program and The Rufford Foundation in UK. My special thanks go to Professor Liu Shaochuang who support me for the CAS-TWAS President scholarship program in University of Chinese Academy of Sciences and guidance, supervisions and encouragements were the most valuable insights to my research. We are grateful to Dr Rich Reading, Dr Petra Kaczensky and Dr John Ewen for providing comments and corrections on an earlier and final version of the manuscripts. I would thank my lab-colleagues at Institute of Remote Sensing and Digital Earth, Chinese Academy of Sciences for their friendship and cooperation during study period. 


\section{Conflicts of Interest}

The authors declare no conflicts of interest regarding the publication of this paper.

\section{References}

[1] Safriel, U., Adeel, Z., Niemeijer, D., Puigdefabregas, J., White, R., Lal, R., Winslow, M., Ziedler, J., Prince, S., Archer, E., King, C., Shapiro, B., Wessels, K., Nielsen, T., Portnov, B., Becker-Reshef, I., Thonnell, J., Lachman, E. and McNab, D. (2019) Dryland Systems, Ecosystems and Human Well-Being: Current State and Trends. Findings of the Condition and Trends Working Group. 623-662.

[2] Davis, P.S., Finarelli, J. and Coates, M. (2012) Davis et al SI 2012. Conserving Dryland Distributions.

[3] Shiirevdamba, T., Shagdarsuren, O., Erdenejav, G., Amgalan, L. and Tsetsegmaa, T.S. (1997) Mongolian Red Book. Admon Printing, Ulaanbaatar. (In Mongoliana)

[4] Tulgat, R. and Schaller, G.B. (1992) Status and Distribution of Wild Camels (Camelus ferus). Biological Conservation, 62, 11-19. https://doi.org/10.1016/0006-3207(92)91147-K

[5] Yadamsuren, A., Dulamtseren, E. and Reading, R.P. (2012) Conservation Status and Management of Wild Camels in Mongolia. In: Knoll, E. and Burge, P., Eds., Camels in Asia and North Africa: Interdisciplinary Perspectives on Their Significance in Past and Present, Austrian Academy of Science, Vienna, 45-54.

[6] Yadamsuren, A., Gunin, P.D. and Jirnov, L.V. (2012) Problems of Maintaining a Sustainable Population of Wild Camels (Camelus ferus, Przewalski) in Mongolia. Ecosystems of Central Asia: Research, Conservation, Rational Use. Kyzyl. 202-205.

[7] Hare, J. (1997) The Wild Camel (Camelus bactrianus ferus) in China: The Need for Urgent Action. Oryx, 31, 45-48. https://doi.org/10.1046/j.1365-3008.1997.d01-2.x

[8] Reading, R.P., Blumer, E.S., Mix, H. and Adiya, Y. (2005) Wild Bactrian Camel Conservation. Proceedings of the Symposium "Ecosystem Research in the Arid Environments of Central Asia: Results, Challenges, and Perspectives", Ulaanbaatar, 23-24 June 2004, 91-100.

[9] McCarthy, T.M. (2000) Ecology and Conservation of Snow Leopards, Gobi Brown Bears and Wild Bactrian Camels in Mongolia. Doctor of Philosophy Ph.D. Thesis, University of Massachusetts, Amherst.

[10] Bannikov, A. (1976) The Wild Camels of the Gobi. Wildlife, 18, 398-403.

[11] Kaczensky, P., Adiya, Y., von Wehrden, H., Mijiddorj, B., Walzer, C., et al. (2014) Space and Habitat Use by Wild Bactrian Camels in the Transaltai Gobi of Southern Mongolia. Journal of Biological Conservation, 169, 311-318. https://doi.org/10.1016/j.biocon.2013.11.033

[12] Schmidt-Nielsen, K., Schmidt-Nielsen, B., et al. (1956) Body Temperature of the Camel and Its Relation to Water Economy. American Journal of Physiology, 188, 103-112. https://doi.org/10.1152/ajplegacy.1956.188.1.103

[13] Zhirnov, L.V., Gunin, P.D. and Жирнов, A.Y. (2011) The Wild Camels in Central Asia. Monograph, Moscow, 180.

[14] Von Wehrden, H., Wesche, K. and Hilbig, W. (2006) Plant Communities of the Mongolian Transaltay Gobi. Feddes Repertorium, 117, 526-570. https://doi.org/10.1002/fedr.200611110

[15] Phillips, S.J. and Dudík, M. (2008) Modeling of Species Distributions with Maxent: 
New Extensions and a Comprehensive Evaluation. Ecography, 31, 161-175. https://doi.org/10.1111/j.0906-7590.2008.5203.x

[16] Yadamsuren, A. (2013) Grazing and Feeding in the Wild Camel (Camelus ferus) Habitat in Mongolia. Proceedings of the Institute of Biology, Ulaanbaatar, No. 29, 108-114.

[17] Fynn, R.W., Chase, M. and Roder, A. (2014) Functional Habitat Heterogeneity and Large Herbivore Seasonal Habitat Selection in Northern Botswana. South African Journal of Wildlife Research, 44, 1-15. https://doi.org/10.3957/056.044.0103

[18] Elith, J., Phillips, S.J., et al. (2011) A Statistical Explanation of MaxEnt for Ecologists. Diversity and Distributions, 17, 43-57. https://doi.org/10.1111/j.1472-4642.2010.00725.x

[19] Fielding, A.H. and Bell, J.F. (1997) A Review of Methods for the Assessment of Prediction Errors in Conservation Presence/Absence Models. Environmental Conservation, 24, 38-49. https://doi.org/10.1017/S0376892997000088

[20] Hernandez, P.A., Graham, C.H., Master, L.L. and Albert, D.L. (2006) The Effect of Sample Size and Species Characteristics on Performance of Different Species Distribution Modeling Methods. Ecography, 29, 773-785.

https://doi.org/10.1111/j.0906-7590.2006.04700.x 